\title{
Vitamin D and Ischaemic Heart Disease: A Casual or A Causal Association?
}

\section{Commentary on: "Raslan E et al. Association of Vitamin D Deficiency with Chronic Stable Angina: A Case-Control Study"}

\author{
Damiano Rizzoni ${ }^{1,2}$ (D) $\cdot$ Marco Rizzoni ${ }^{3} \cdot$ Matteo Nardin $^{1}$
}

Received: 9 January 2019 / Accepted: 16 January 2019 / Published online: 23 January 2019

(c) Italian Society of Hypertension 2019

Keywords Vitamin D $\cdot$ Ischemic heart disease $\cdot$ Angina $\cdot$ Coronary arteries

\section{Introduction}

The aim of the study by Raslan E et al. [1], published in the present issue of High Blood Pressure and Cardiovascular Prevention, was to assess vitamin D status among patients with chronic stable angina and to compare it with that of a matched control group. The Authors' conclusion is that there is a significant association between vitamin D deficiency and the occurrence of chronic stable angina [1].

This is a non-randomized, case-control study, mainly based on interviewing questionnaires, and performed in a relative limited number of patients with angina pectoris as well as controls ( $n=42$ vs. 42 ). The study limitations are properly recognized by the Authors themselves; among them it should be mentioned the possibility of an imperfect matching of patients and controls; a selection bias might have occurred, as patients were selected from a tertiary hospital pool. Possible confounders, such as smoking, physical activity, hypertension and diabetes might have influenced the results obtained.

Damiano Rizzon

damiano.rizzoni@unibs.it

1 Department of Clinical and Experimental Sciences, Clinica Medica, University of Brescia, c/o 2a Medicina Spedali Civili di Brescia, Piazza Spedali Civili 1, 25100 Brescia, Italy

2 Division of Medicine, Istituto Clinico Città di Brescia, Brescia, Italy

3 Department of Information Engineering, University of Brescia, Brescia, Italy
In addition, the case-control nature of the study, that did not include longitudinal observation or drug interventions, does not allow a proper evaluation of the causal relationships between the investigated variable (vitamin D plasma levels), and the occurrence of angina pectoris; however it is interesting to postulate a possible role of vitamin D deficiency as a potentially modifiable and underestimated risk factor for ischemic heart disease [1,2].

The possible association between vitamin D circulating levels and coronary heart disease was addressed also in other previous recent studies [3-7], however, the issue is intriguing and controversial.

Vitamin D, a fat-soluble prohormone, has wide-ranging roles in the regulation of many physiological processes through their interactions with the vitamin D receptors [2]. It plays a major role in bones and calcium metabolism. Vitamin D deficiency is not uncommon and it has been associated with many health-related issues including skeletal and non-skeletal complications. The association of low vitamin $\mathrm{D}$ and cardiovascular diseases and risk factors has been explored in both animal and human studies. However, studies and trials on the effect of vitamin D supplementation on cardiovascular risk factors and hypertension are, in general, conflicting with inconsistent results [2].

\section{Studies Addressing Vitamin D Deficiency and Coronary Artery Disease}

The association of vitamin D deficiency with coronary artery disease has been investigated in previous studies [8-10]. One of the first reports is a Danish study conducted 
in 1978, which found a significant association between low vitamin D levels and angina and myocardial infarction [11]. Moreover, in a multicenter United States cohort study that evaluated patients admitted with acute coronary syndrome, the Authors reported that about $95 \%$ of patients had low vitamin D levels [12].

Dziedzic et al. observed low circulating vitamin D levels in patients with a history of myocardial infarction [13], while Roy et al. reported that severe vitamin D deficiency was associated with an increased risk of acute myocardial infarction even after adjustment for other risk factors in a case-control study, [14]. Verdoia et al. in a cohort of about 1500 patients undergoing percutaneous coronary intervention reported a significant and independent role of Vitamin $\mathrm{D}$ deficiency in predicting coronary artery disease and severe coronary artery disease, defined as left main and/or triple-vessel disease [15].

Even larger studies have been performed. In particular, the Health Professionals Follow-up Study included 18,225 persons, with a follow-up of 10-year; participants with normal vitamin D levels had half the risk of myocardial infarction in [16].

In a large prospective study $(n=10,170)$, low vitamin $\mathrm{D}$ levels were found to be associated with an increased risk of ischemic heart disease, myocardial infarction, and early death during 9 years of follow-up [17]. Moreover,, in a metaanalysis of 18 studies, low vitamin D levels were associated with an increased risk of ischemic heart disease and early death [17].

In a clinical setting similar to that addressed by Raslan E et al. [1], Jarrah MI et al. [3] measured serum levels of vitamin D using radioimmunoassay in 186 Jordanian patients who underwent investigative coronary catheterization. Of these patients, 133 were suffering from coronary artery stenosis. The study, however, did not show any association between vitamin $\mathrm{D}$ abnormalities and the incidence or the reoccurrence of coronary artery stenosis [3].

On the contrary, a large Norwegian study [4] demonstrated that plasma 25-hydroxyvitamin D concentrations were inversely associated with cardiovascular mortality and nonlinearly (U-shaped) associated with all-cause mortality A total of 895 (21.8\%) deaths, including 407 (9.9\%) from cardiovascular disease causes, occurred during a mean follow-up of 11.9 years.

The effect of vitamin D supplementation on angina episodes in Vitamin D deficient patients with chronic stable angina on medical management was evaluated in an intervention study [5]. Significant $20 \%(p<0.05)$ reduction in anginal episodes and $17.24 \%(p<0.05)$ reduction in use of sub-lingual nitrates was noted after Vitamin D supplementation. The benefits were independent of blood pressure values, heart rate and medications, thus, possibly attributing to vitamin D supplementation, since no reduction in angina episode was observed in a control group of patients with angina and normal circulating levels of vitamin $\mathrm{D}$, in which no vitamin D supplementation was implemented [5].

In a cross-sectional, observational study, fifty females with normal epicardial coronary arteries who presented with typical symptoms of rest or effort angina and 41 healthy age-matched female controls were included [6]. In patients with coronary syndrome $\mathrm{X}, 25-\mathrm{OH}$ vitamin $\mathrm{D}$ levels were lower than those in controls; moreover, $25-\mathrm{OH}$ vitamin D deficiency was also associated with higher levels of peak diastolic blood pressure during exercise [6].

\section{Possible Role of Vitamin D Deficiency in the Pathogenesis of Coronary Artery Disease}

Vitamin D deficiency may play a crucial role in the pathogenesis of coronary artery disease at several levels, due to the fact that its receptors are present in different tissues. Vitamin D may be involved in the regulation of blood pressure, through different mechanisms, including the renin-angiotensin system and the modulation of vascular smooth muscle cells growth and proliferation [7]: Kawashima have previously shown the presence of a receptor to 1,25-dihydroxyvitamin $\mathrm{D}$ in smooth muscle tissue, supporting a potential role for Vitamin D in the regulation of vascular contraction and blood pressure [18].

Some mechanisms that may explain the preventive effects of Vitamin D against hypertension are summarized in Table 1.

Table 1 Mechanisms that can explain the preventive effects of Vitamin D against hypertension

1. Direct suppression of the renin-angiotensin system as $1,25(\mathrm{OH}) 2 \mathrm{D}$ functions as a negative endocrine regulator of renin gene expression in vivo

2. Decreases intimal thickening of blood vessels by inhibiting the accumulation of extracellular matrix within the inner vessel wall through its inhibitory effect on MMP

3. Decreases arterial stiffness by causing upregulation of nitric oxide synthesis which is synthesized by endothelium

Adapted from reference 7

MMP metalloproteinases 
Moreover vitamin $\mathrm{D}$ has been reported to be able to modulate endothelial function, inflammatory processes [19-22] and thrombotic events [23]. Serum levels of vitamin D have been shown to be inversely associated with the extent of vascular calcifications [24-26] and with carotid intima-media thickness [27].

In a double-blinded randomized controlled trial Vitamin D supplementation has been found to decrease arterial stiffness through the reduction of the mean pulse wave velocity from $5.41 \pm 0.73 \mathrm{~m} / \mathrm{s}$ at baseline to $5.33 \pm 0.79 \mathrm{~m} / \mathrm{s}$ $(p=0.031)$ [28].

Evidences indicated that low Vitamin D status adversely affects cardiac function [7]. Similarly, reversal of cardiomegaly by calcium and Vitamin D supplementation has been described in children with rickets [29] and in an adult with congestive heart failure [30].

An effect of Vitamin D on mechanisms involved in atheroma formation has also been described. In particular, vitamin D inhibits the uptake of cholesterol by macrophages and, in case of Vitamin D deficiency, cholesterol uptake by macrophages is promoted and these so-called "foam cells" may invade endothelium, forming atheromatous plaque and promoting atherosclerosis [31].

Vitamin D deficiency has also been associated with decreased levels of high-density lipoprotein and apolipoprotein A-1, with consequent atherosclerosis promotion [32].

Positive associations have been reported between interleukin-6 (a marker of inflammation, predictor of subsequent risk of cardiovascular disease) and insulin resistance [33]. The latter is a risk factor for type 2 diabetes, which is itself inversely related to Vitamin D status [34] and predisposes to coronary artery disease. Among diabetes patients, in which a pro-inflammatory and pro-thrombotic status is present, lower vitamin $\mathrm{D}$ levels has been shown independently related to coronary artery disease and its extension [35].

\section{Areas of Uncertainty}

However, despite abundant evidence concerning the involvement of Vitamin D deficiency in the pathogenesis of coronary artery disease, very few well-conducted, randomized controlled trials address this issue.

In addition, several randomized controlled trials which have investigated the role of Vitamin D supplementation in improving cardiovascular outcome, mostly in high-risk population have failed to provide any conclusive results [7, $36,37]$.

A systematic review of longitudinal studies examining the relationship of Vitamin D supplementation on cardiometabolic outcomes, including hypertension, cardiovascular disease and type 2 diabetes, was conducted by Pittas et al. [38]. The conclusion was that the association between vitamin D status and cardiometabolic outcome is uncertain. In particular, four trials showed that Vitamin D supplementation does not influence cardiometabolic outcomes [7, 38].

A recent randomized controlled trial of 200 hypertensive patients with vitamin D deficiency have examined the effect of Vitamin D supplementation on $24 \mathrm{~h}$ systolic ambulatory blood pressure monitoring values and cardiovascular risk factors, showing that there were no significant effects of Vitamin D supplementation on blood pressure and other cardiovascular risk factors; paradoxically an increase in triglyceride levels in the experimental group was observed [39].

Finally, most recent evidence supporting the absence of an impact of vitamin D supplementation on patients outcome is constituted by a nationwide randomized placebocontrolled trial including about 25000 individuals. Subjects were randomized to receive vitamin D supplementation or placebo. Primary outcome were major cardiovascular events and invasive cancer. No reduction in the incidence of major cardiovascular events or of invasive cancer was found in patients taking vitamin D supplementation [40].

\section{Conclusions}

Interrelationships between vitamin D deficiency and coronary heart disease remain elusive, and the causality of such a relationship is still uncertain. Many factors and mechanisms are possibly involved; therefore the relations between vitamin D circulating levels and clinical manifestations of ischemic heart disease represent an extremely interesting topic of clinical research, which deserve further and thorough investigation, with large, well-powered randomized controlled trials, also considering its possibly relevant clinic impact, especially in terms of therapeutic targets and possible prevention or regression of coronary heart disease, provided that supplementation with easy and low-cost vitamin $\mathrm{D}$ will be demonstrated to have a positive impact on our health $[2,40]$. The availability of these evidences is mandatory before guidelines might recommend Vitamin D measurement and supplementation for risk stratification and prevention of coronary artery disease.

\section{Compliance with ethical standards}

Conflict of interest On behalf of all authors, the corresponding author states that there is no conflict of interest.

\section{References}

1. Raslan E, Soliman SSA, Nour ZA, Ahmed D, Eid N, Saad S. Association of vitamin D deficiency with chronic stable angina: a case control study. High Blood Press Cardiovasc Prev. 2019;5:1-4. 
2. Kheiri B, Abdalla A, Osman M, Ahmed S, Hassan M, Bachuwa G. Vitamin D deficiency and risk of cardiovascular diseases: a narrative review. Clin Hypertens. 2018;24:9.

3. Jarrah MI, Mhaidat NM, Alzoubi KH, Alrabadi N, Alsatari E, Khader Y, Bataineh MF. The association between the serum level of vitamin D and ischemic heart disease: a study from Jordan. Vasc Health Risk Manag. 2018;14:119-27.

4. Degerud E, Nygård O, de Vogel S, Hoff R, Svingen GFT, Pedersen ER, Nilsen DWT, Nordrehaug JE, Midttun Ø, Ueland PM, Dierkes J. Plasma 25-hydroxyvitamin D and mortality in patients with suspected stable angina pectoris. J Clin Endocrinol Metab. 2018;103:1161-70.

5. Sagarad SV, Sukhani N, Machanur B, Patil S. Effect of Vitamin $\mathrm{D}$ on anginal episodes in vitamin $\mathrm{D}$ deficient patients with chronic stable angina on medical management. J Clin Diagn Res. 2016;10:24-6.

6. Babür Güler G, Güler E, Hatipoğlu S, Güneş HM, Geçmen Ç, Demir GG, Barutçu İ. Assessment of $25-\mathrm{OH}$ vitamin D levels and abnormal blood pressure response in female patients with cardiac syndrome X. Anatol J Cardiol. 2016;16:961-6.

7. Aggarwal R, Akhthar T, Jain SK. Coronary artery disease and its association with Vitamin D deficiency. J Midlife Health. 2016;7:56-60.

8. Milazzo V, De Metrio M, Cosentino N, Marenzi G, Tremoli E. Vitamin D and acute myocardial infarction. World J Cardiol. 2017;9:14-20.

9. Anderson J, May H, Horne B, Bair T, Hall N, Carlquist J, Lappé $\mathrm{D}$, Muhlestein J. Relation of vitamin D deficiency to cardiovascular risk factors, disease status, and incident events in a general healthcare population. Am J Cardiol. 2010;106:963-8.

10. Aleksova A, Belfiore R, Carriere C, Kassem S, La Carrubba S, Barbati G, Sinagra G. Vitamin D deficiency in patients with acute myocardial infarction: an Italian single-center study. Int J Vitam Nutr Res. 2015;85:23-30.

11. Lund B, Badskjaer J, Lund B, Soerensen O. Vitamin D and ischaemic heart disease. Horm Metab Res. 1978;10:553-6.

12. Lee JH, Gadi R, Spertus JA, Tang F, O'Keefe JH. Prevalence of vitamin $\mathrm{D}$ deficiency in patients with acute myocardial infarction. Am J Cardiol. 2011;107:1636-8.

13. Dziedzic E, Gąsior J, Pawłowski M, Dąbrowski M. Association of Vitamin D Deficiency and Degree of coronary artery disease in cardiac patients with type 2 diabetes. J Diabetes Res. 2017;2017:1-11.

14. Roy A, Lakshmy R, Tarik M, Tandon N, Reddy KS, Prabhakaran D. Independent association of severe vitamin D deficiency as a risk of acute myocardial infarction in Indians. Indian Heart J. 2015;67:27-32.

15. Verdoia M, Schaffer A, Sartori C, Barbieri L, Cassetti E, Marino $P$, Galasso G, De Luca G. Vitamin D deficiency is independently associated with the extent of coronary artery disease. Eur J Clin Invest. 2014;44:634-42.

16. Giovannucci E, Liu Y, Hollis B, Rimm E. 25-hydroxyvitamin $\mathrm{D}$ and risk of myocardial infarction in men: a prospective study. Arch Intern Med. 2008;168:1174-80.

17. Brøndum-Jacobsen P, Benn M, Jensen GB, Nordestgaard BG. 25-Hydroxyvitamin D levels and risk of ischemic heart disease, myocardial infarction, and early death. Arter Thromb Vasc Biol. 2012;32:2794-802.

18. Kawashima H. Receptor for 1,25-dihydroxyvitamin D in a vascular smooth muscle cell line derived from rat aorta. Biochem Biophys Res Commun. 1987;146:1-6.

19. Tarcin O, Yavuz DG, Ozben B, Telli A, Ogunc AV, Yuksel M, Toprak A, Yazici D, Sancak S, Deyneli O, Akalin S. Effect of vitamin D deficiency and replacement on endothelial function in asymptomatic subjects. J Clin Endocrinol Metab. 2009;94:4023-30.
20. Cardus A, Panizo S, Encinas M, Dolcet X, Gallego C, Aldea M, Fernandez E, Valdivielso JM. 1,25-dihydroxyvitamin D3 regulates VEGF production through a vitamin D response element in the VEGF promoter. Atherosclerosis. 2009;204:85-9.

21. Norman PE, Powell JT. Vitamin D, shedding light on the development of disease in peripheral arteries. Arterioscler Thromb Vasc Biol. 2005;25:39-46.

22. Schleithoff SS, Zittermann A, Tenderich G, Berthold HK, Stehle P, Koerfer R. Vitamin D supplementation improves cytokine profiles in patients with congestive heart failure: a double-blind, randomized, placebo-controlled trial. Am J Clin Nutr. 2006;83:754-9.

23. Aihara K, Azuma H, Akaike M, Ikeda Y, Yamashita M, Sudo T, Hayashi H, Yamada Y, Endoh F, Fujimura M, Yoshida T, Yamaguchi H, Hashizume S, Kato M, Yoshimura K, Yamamoto Y, Kato S, Matsumoto T. Disruption of nuclear vitamin D receptor gene causes enhanced thrombogenicity in mice. J Biol Chem. 2004;279:35798-802.

24. Sigmund CD. Regulation of renin expression and blood pressure by vitamin D(3). J Clin Invest. 2002;110:155-6.

25. Barreto DV, Barreto FC, Liabeuf S, Temmar M, Boitte F, Choukroun G, Fournier A, Massy ZA. Vitamin D affects survival independently of vascular calcification in chronic kidney disease. Clin J Am Soc Nephrol. 2009;4:1128-35.

26. Jono S, Nishizawa Y, Shioi A, Morii H. 1,25-Dihydroxyvitamin D3 increases in vitro vascular calcification by modulating secretion of endogenous parathyroid hormone-related peptide. Circulation. 1998;98:1302-6.

27. Watson KE, Abrolat ML, Malone LL, Hoeg JM, Doherty T, Detrano R, Demer LL. Active serum vitamin D levels are inversely correlated with coronary calcification. Circulation. 1997;96:1755-60.

28. Dong Y, Stallmann-Jorgensen IS, Pollock NK, Harris RA, Keeton D, Huang Y, et al. A 16-week randomized clinical trial of 2000 international units daily Vitamin D3 supplementation in black youth: 25-hydroxyvitamin D, adiposity, and arterial stiffness. J Clin Endocrinol Metab. 2010;95:4584-91.

29. Uysal S, Kalayci AG, Baysal K. Cardiac functions in children with Vitamin D deficiency rickets. Pediatr Cardiol. 1999;20:283-6.

30. Connor TB, Rosen BL, Blaustein MP, Applefeld MM, Doyle LA. Hypocalcemia precipitating congestive heart failure. N Engl J Med. 1982;307:869-72.

31. Oh J, Weng S, Felton SK, Bhandare S, Riek A, Butler B, et al. $1,25(\mathrm{OH}) 2$ Vitamin $d$ inhibits foam cell formation and suppresses macrophage cholesterol uptake in patients with type 2 diabetes mellitus. Circulation. 2009;120:687-98.

32. Auwerx J, Bouillon R, Kesteloot H. Relation between 25-hydroxyvitamin D3, apolipoprotein A-I, and high density lipoprotein cholesterol. Arterioscler Thromb. 1992;12:671-4.

33. Bastard JP, Jardel C, Bruckert E, Blondy P, Capeau J, Laville M, et al. Elevated levels of interleukin 6 are reduced in serum and subcutaneous adipose tissue of obese women after weight loss. J Clin Endocrinol Metab. 2000;85:3338-42.

34. Pittas AG, Lau J, Hu FB, Dawson-Hughes B. The role of Vitamin $\mathrm{D}$ and calcium in type 2 diabetes. A systematic review and metaanalysis. J Clin Endocrinol Metab. 2007;92:29.

35. Nardin M, Verdoia M, Schaffer A, Barbieri L, Marino P, De Luca G, Novara Atherosclerosis Study Group (NAS). Vitamin D status, diabetes mellitus and coronary artery disease in patients undergoing coronary angiography. Atherosclerosis. 2016;250:114-21.

36. Sokol SI, Srinivas V, Crandall JP, Kim M, Tellides G, Lebastchi $\mathrm{AH}$, et al. The effects of Vitamin D repletion on endothelial function and inflammation in patients with coronary artery disease. Vasc Med. 2012;17:394-404.

37. Donneyong MM, Hornung CA, Taylor KC, Baumgartner RN, Myers JA, Eaton CB, et al. Risk of heart failure among postmenopausal women: a secondary analysis of the randomized trial 
of Vitamin D plus calcium of the women's health initiative. Circ Heart Fail. 2014;14:56.

38. Pittas AG, Chung M, Trikalinos T, Mitri J, Brendel M, Patel K, et al. Systematic review: vitamin D and cardiometabolic outcomes. Ann Intern Med. 2010;152:307-14.

39. Pilz S, Gaksch M, Kienreich K, Grübler M, Verheyen N, Fahrleitner-Pammer A, et al. Effects of Vitamin D on blood pressure and cardiovascular risk factors: a randomized controlled trial. Hypertension. 2015;65:1195-201.
40. Manson JE, Cook NR, Lee IM, Christen W, Bassuk SS, Mora S, Gibson H, Gordon D, Copeland T, D'Agostino D, Friedenberg G, Ridge C, Bubes V, Giovannucci EL, Willett WC, Buring JE, VITAL Research Group. Vitamin D supplements and prevention of cancer and cardiovascular disease. N Engl J Med. 2019;380:33-44. 